\title{
3 Kasım 2020 Tarihinde Gerçekleşen Amerika Birleşik Devletleri Başkanlık Seçiminin Ardından Yaşanan Tartışmalar Işığında Mektupla Oy Verme ve Elektronik Oy Verme Usulleri
}

\author{
Mail Voting And Electronic Voting Procedures in The Light of The Discussions After The United \\ States Presidential Election, Held on November 3, 2020
}

\section{Fatih GÜLER}

Dr. Öğr. Gör., Çanakkale Onsekiz Mart Üniversitesi,

Çan MYO,fatih.guler@comu.edu.tr

https://orcid.org/0000-0002-5365-5700
Makale Başvuru Tarihi: 30.01.2021

Makale Kabul Tarihi: 11.04.2021

Makale Türü: Araştırma Makalesi

\begin{abstract}
Anahtar
Kelimeler:

ÖZET

Mektupla $O y$

Verme,

Demokratik sistemlerde siyasi iktidarların meşruiyet kaynă̆ı adil ve dürüst seçimlerdir. Seçimlerin adil ve dürüst bir şekilde gerçekleşmesi kadar önemli olan diğer bir husus ise seçimlere katılım oranıdır. Seçimler adil ve dürüst bir şekilde gerçekleşse dahi seçime katılım oranı düşük ise bu durum görece bir meşruiyet sorunu teşkil edebilir. Seçime katılım oranı ile siyasi iktidarın meşruiyet oranı arasında doğru bir orantının

Elektronik Oy

Verme, olduğu söylenebilir. Kamu otoriteleri seçimlere katılım oranını arttırmak amactyla elektronik oy kullanma, mektupla oy kullanma gibi bazı yöntemlere başvurmaktadırlar. Türkiyede seçime katılım oranını arttırmak amacıyla yurt dişında yaşayan vatandaşlarımızın oy kullanma yöntemleri arasına 2008 yılında 298 sayll

Katılım Oranı, Kanun'da değişiklik yapılarak mektupla oy kullanma ve elektronik oy verme ilave edilmiştir. Mektupla oy verme ve elektronik oy verme yöntemleri seçime katılma oranını artırmasına ră̆men seçimin güvenilirliği

Amerika Birleșik

Devletleri 2020

Başkanlık Seçimi, üzerinde şüphe oluşturabilme potansiyeline sahiptir. Bu çalışmada, 2020 yll Kasım ayında gerçekleşen Amerika Birleşik Devletleri Başkanlık seçimi ardından başlayan tartışmalar ışı̆̆ında, elektronik oy verme ve mektupla oy verme yöntemleri değerlendirecektir.
\end{abstract}

298 sayılı Kanun,

Keywords:

Voting by Mail,

Electronic Voting,

Turnout Rate,

United States 2020

Presidential

Election,

Law No. 298,

\begin{abstract}
The legitimacy source of political powers in democratic systems is fair and honest elections. Another issue that is just as important as the fair and honest conduct of the elections is the voter turnout rate of elections. Even if the elections are held fairly and honestly, if the voter turnout rate is low, this may pose a relative legitimacy problem. It can be said that there is a direct proportion between the voter turnout rate of elections and the legitimacy rate of the political power. Public authorities use some methods such as electronic voting and mail-in voting in order to increase their voter turnout rate in elections. In order to increase abroad voter turnout rate in our country, the Law on Basic Provisions of Elections and Voter Registers was amended in 2008, mail voting and electronic voting were added. Although mail-in voting and electronic voting methods increase voter turnout rates, they have the potential to cast doubt on the reliability of the election. In this study, in light of the discussions that started after the presidential election of the United States of America in November 2020, electronic voting and mail voting methods will be evaluated.
\end{abstract}




\section{GIRISS}

Demokratik sistemlerde siyasi iktidarların meşruiyet kaynağı adil ve dürüst seçimlerdir. Seçimlerin adil ve dürüst bir şekilde gerçekleşmesi kadar önemli olan diğer bir husus ise seçimlere katılım oranıdır. Seçimlere katılma oranı bir ülkede gerçekleştirilen herhangi bir seçim için, oy kullanan seçmen sayısının (geçersiz oylar dâhil) seçim otoritesi tarafından kabul edilen kayıtlı seçmen sayısına oranı olarak tanımlanabilir.

Bir ülkede siyasal geleceğin oluşturulması ve devamlılı̆̆ın sağlanması için yurttaşların üzerine düşen temel görev, demokratik sistem içerisinde her türlü meşru araçtan faydalanarak siyasal katılımın gerçekleştirilmesidir (Yücel, 2013:33). Adil ve dürüst seçimlere katılma oranı o ülkenin demokratikleşme düzeyinin göstergeleri arasında yer almaktadır (Sarıbay, 1998:69). Bazı araştırmacılar seçimlere katılma oranı ile toplumların gelişmişlik düzeyi arasında ilişki kursalar da bu ilişki her zaman doğrusal olmayabilir (Arslan, 2007:4). Zira seçime katılma oranlarındaki gerilemenin küresel bir eğilim haline gelmesiyle birlikte seçime katılma oranlarının demokrasinin kalitesi ile ilgili olmayabileceği ve seçimlere yüksek katılma oranının mutlaka sağlıklı bir demokrasiye işaret etmeyebileceği göz önünde bulundurulmalıdır (Kiriş, 2015:32).

Seçimler adil ve dürüst bir şekilde gerçekleşse dahi seçime katılım oranı eğer düşük ise bu durum görece bir meşruiyet sorunu teşkil edebilir. Seçime katılım oranı ile siyasi iktidarın meşruiyet oranı arasında doğru orantı olduğu söylenebilir. Seçimlerin adil ve dürüst bir şekilde gerçekleşmesi şartıyla, seçimlere katılmanın zorunlu olmasının hukuki bir müeyyideye bağlanması durumlarından bağımsız olarak, bir değerlendirme yapıldığında, seçimlere katılım oranın yüksek olması siyasi iktidarların meşruiyeti üzerinde olumlu bir etki oluşturacağı açıktır. Bununla birlikte siyasi iktidarlar ile vatandaşlar arasındaki siyasi bağı da kuvvetlendirecektir. Aynı şekilde seçimlere katılım oranın düşük olması, siyasi iktidarlar ile seçime katılmayan toplumsal kesimler arasındaki siyasi bağın tamamen kopması sonucunu doğurabilecektir.

Kamu otoriteleri tarafından seçimlere katılma oranını arttırmaya yönelik olarak muhtelif uygulamalar tercihli ya da eş zamanlı olarak uygulanabilmektedir. Bu kapsamda seyyar sandıklarda oy kullanma, gümrük kapılarında oy kullanma ve yurt dışı temsilciliklerde oy kullanma gibi yöntemlerin yanı sıra belirli bir yer ve/veya zamana bağlı olmadan oy kullanmaya imkân sağlayan alternatif oy verme usulleri de geliştirilmektedir. Bu durum, oy verme usulleri ile ilgili akademik yazın ve uygulamadaki tartışma ve değerlendirmeleri arttırmaktadır.

\section{MEKTUPLA OY VERME VE ELEKTRONIK OY VERME}

Kanun koyucular, vatandaşların seçimlere katılımını arttırmak amacıyla klasik oy verme yöntemi olan sandıkta oy verme yöntemine ilave olarak mektupla oy verme, elektronik oy verme, vekâletle oy verme gibi alternatif ve/veya ilave oy verme yöntemleri ihdas etmektedirler (Gözler, 2020:790).

Mektupla oy verme usulü, seçim otoritesi tarafından özel olarak imal ettirilen oy pusulaları ile oy zarflarının, gerekli güvenlik önlemleri aldıktan sonra seçimlerin yapılacağ 1 günden makul bir süre öncesinde seçmenin kayıtlı olduğu adresine gönderilmesi, mektubu alan seçmenin de oy pusulasındaki tercih ettiği bölümü işaretleyerek zarfı, tekrardan geri göndermesidir. Mektubun yani kullanılan oyun geçerli sayılabilmesi için seçim günü sandıkta oy verme süresinin sonuna kadar seçim otoritesine ulaşacak şekilde posta ile gönderilmesi gerekmektedir.

Mektupla oy kullanma uygulaması, hiç şüphesiz oy kullanmada bir kolaylık sağlamaktadır. Ayrıca dolaylı olarak seçimlere katılma oranını da artırmaktadır. Elbette ki bu oran artı̧̧ı devletlere ve zamana göre değişiklik gösterebilmektedir. Örneğin Amerika Birleşik Devletlerinde uygulanan mektupla oy kullanma yönteminin seçimlere katılma anlamında önemli bir teşvik olduğu (Southwell ve Burchett, 2000:72) tespit edilmiştir. Bu kapsamda 1980-2004 yılları arası başkanlık seçimlerinde ve 1982 - 2006 yılları arası ara seçimlerinde katılım oranlarını sadece Oregon eyaletinde bile \%10 oranında arttırdığı tespit edilmiştir (Richey, 2008:902). Bununla beraber mektupla oy verme yönteminin seçimlere katılım oranını artırmaktan ziyade hali hazırda oy kullanan seçmenin, oyunu kullanma prosedürlerini kolaylaştırıp sadeleştirerek bu seçmen grubunu oy kullanma sistemi içerisinde kalmasını sağladığına yönelik veriler de bulunmaktadır (Berinsky vd., 2001:178).

Oy kullanma yöntemlerinden bir başkası olan elektronik seçim, dijital araçlar ve platformlar üzerinden siyasi bir konu hakkında görüş bildirmek amacıyla elektronik yollarla seçmenlerin ve adayların sicillerinin yer aldığ 1 elektronik sistemlerde oy kullanmak ve seçim sonuçlarının bu sistemden yayınlaması şeklinde tanımlanabilir (Çokluk ve Özdemir, 2019:107). Elektronik seçim teknolojileri arasında delikli kartlar, optik okuma sistemleri, oy kullanma kioskları, internet üzerinden oy kullanma yer almaktadır (Telciler, 2017:109). 
Elektronik seçim yönteminin geleneksel sandıkta oy kullanma yöntemine göre daha hızlı, daha ucuz, daha erişebilir olması (Bilgin vd., 2009:75), geleneksel seçim yöntemlerindeki insan hatalarını en aza indirecek olması (Erdem ve Erkaymaz, 2009:136), elektronik seçim yöntemindeki seçmenlerin ve oyların gizliliğinden ve seçimin güvenilirliğinden ve doğruluğuna yönelik makul şüpheyi ortadan kaldırmamaktadır (Çetinkaya ve Çetinkaya, 2006:7). Elektronik oy verme sistemleri Hindistan ve Brezilya gibi kalabalık nüfusa sahip ve gelişmekte olan ülkelerde başarılı ve yaygın bir uygulama (Akın, 2006:45) alanına sahip olmasına rağmen, seçimin güvenilirliği ve oyların gizliliği odağındaki makul şüpheyi ortadan kaldıracak güçte değildir. İdeal bir elektronik seçim sistemi ancak iyi bir kodlama, yazılım mühendisliği, hukuk, ekonomi ve diğer sosyal bilim uzmanlarının multidisipliner perspektifleri ile oluşturulabilir (Erzurumlu ve Koloğlu, 2017:3). Ancak ne kadar başarılı olursa olsun elektronik ortam her zaman bir güvenlik sorununu da beraberinde getirecektir.

\section{TÜRK SEÇIM MEVZUATINA MEKTUPLA OY VERME VE ELEKTRONIK OY VERME USULLERININ EKLENMESI}

2008 y1lında 5749 sayılı Kanunun 10. maddesi ile 298 sayılı Kanunun 94. maddesine eklenen hükümlerle yurt dışında yaşayan vatandaşlarımızın oy kullanım oranını artırmak ve oy kullanmalarını kolaylaştırmak amacıyla daha önceden beri uygulanagelen sandıkta oy verme ve gümrük kapılarında oy verme yöntemlerine mektupla oy verme ve elektronik ortamda oy verme yöntemleri de ilave edilmiştir.

298 sayılı Kanunun 94. maddesinde elektronik oylamanın sadece genel esasları belirlenmiştir. Buna göre Yüksek Seçim Kurulu, yurt dışı seçmenlerin seçimin yapılacağı tarihin otuz gün öncesinden başlayarak seçim günü sandıkta oy kullanma süresi sonuna kadar Türkiye Cumhuriyeti kimlik numarası aracılığıyla elektronik ortamda oy kullanabilmelerini sağlamak amacıyla gerekli teknik alt yapıyı kurmaya; güvenli oy kullanılabilmesi amacıyla seçmenler için şifre veya benzeri güvenlik tedbirleri ile mükerrer oy kullanılmasını engelleyecek önlemleri almaya yetkilidir. Daha sonra Anayasa Mahkemesi kararıyla iptal edilen 298 sayılı Kanunun 94. maddesinin mektupla oy kullanma usulünde, elektronik oylamaya benzer şekilde, sadece genel esaslar belirlenmiştir. Buna göre Yurt Dışı İlçe Seçim Kurulu oy pusulası ile oy zarflarını, seçimlerin yapılacağı günün yetmişbeş gün öncesinden seçmenin yurt dışında kayıtlı olduğu adresine göndermesinin ardından mektubu alan seçmen, oy pusulasındaki tercih ettiği bölümü işaretleyip zarfi seçim günü oy verme süresinin bitiminden önce Yurt Dışı İlçe Seçim Kuruluna ulaşacak şekilde posta ile gönderir. Aynı düzenlemeye göre seçim günü oy verme süresinin bitiminden sonra gelen mektuplar geçersiz sayılarak, tutanakla tespit edildikten sonra yakılarak imha edilecektir.

6304 sayılı Kanunla 298 sayılı Kanunun 94. maddesinde değişiklikler yapılmıştır. Bu değişiklikler ile yurt dış1 seçmenlerin oy kullanmasında hangi oylama yöntemlerinin birlikte veya ayrı ayrı uygulanacağına, seçim türüne ve yabancı ülkenin durumuna göre, Dışişleri Bakanlığının görüşü alınarak Yüksek Seçim Kurulunca karar verilmesi ilkesi benimsenmiştir.

5749 sayılı Kanunun Türkiye Büyük Millet Meclisi Genel Kurulu görüşmeleri esnasında mektupla oy verme konusunda ciddi tartışmalar ve görüşmeler yaşanmasına rağmen, elektronik oy verme ile ilgili ciddi tartışma yaşanmamıştır. Bunun en önemli sebebinin elektronik oylamanın çok kısa bir süre içerisinde gündeme alınmasının mümkün olmamasına rağmen, mektupla oy kullanmanın uygulama kapasitesinin mümkün olmasından kaynaklı olduğu söylenebilir (TBMM Genel Kurulu, 2008a).

5749 sayılı Kanun tasarısının geneli üzerine Türkiye Büyük Millet Meclisi Anayasa Komisyonunda gerçekleştirilen görüşmeleri esnasında mektupla oy verme usulünde vatandaşların baskı altında kalma ihtimaline özellikle dikkat çekilmiştir. Ancak buna rağmen kanun tasarısı oybirliği ile TBMM Genel Kurulu'na sevk edilmiştir. 5749 sayılı Kanun tasarısının Türkiye Büyük Millet Meclisi Anayasa Komisyonu raporunda, mektupla oy verme ya da diğer hususlarıyla ilgili bir muhalefet şerhi bulunmamaktadır (TBMM Anayasa Komisyonu, 2008).

5749 sayılı Kanun tasarısının TBMM Genel Kurulunda görüşülmesi esnasında mektupla oy kullanma ile ilgili karşıı görüşler ifade edilmiştir. Mektupla oy kullanmanın gizli oy ilkesini zedeleyeceği işaret edilerek, mektupla oy verme usulünün tasarı metninden çıkartılmasına yönelik önergeler verilmiştir (TBMM Genel Kurulu, 2008b). Mektupla oy verme usulünü de kapsayan 5749 sayılı Seçimlerin Temel Hükümleri ve Seçmen Kütükleri Hakkında Kanunda Değişiklik Yapılmasına Dair Kanun, 22.3.2008 tarihinde Resmi Gazetede yayımlanıp yürürlüğü girmesinin ardından iptal davasına konu edilerek Anayasa Mahkemesinin gündemine getirilmiştir. 
Anayasa Mahkemesi 5 Temmuz 2008 tarih ve 26927 sayılı Resmi Gazetede yayımlanan 29 Mayıs 2008 tarih Esas No: 2008/33 Karar No: 2008/133 sayll kararla 13.03.2008 tarih ve 5749 say1l Kanunun 10. maddesi ile 298 sayılı Kanunun 94. maddesine eklenen mektupla oy verme yöntemini iptal etmiştir. Anayasa Mahkemesi kamu otoritesinin yurt dışında ikamet eden vatandaşlarımızın oy verme hakları ile ilgili pozitif yükümlülüğüne vurgulamakla birlikte, bu konuyla ilgili kullanılacak argümanların Anayasa'da belirlenen seçim ilkelerine uygun ve uygulanabilir nitelikteki tedbirlerle uyumlu olması gerektiğine işaret etmiştir.

Anayasa Mahkemesi mektupla oy kullanma yönteminin, seçmenin oyunu kullanırken aile bireylerinden ve sosyal çevresinden gelebilecek her türlü etkiye açı olma ihtimalini göz önünde bulundurarak, mektupla oy kullanma yönteminin seçmenin iradesini korumaya elverişli nitelikte bulunmadığına işaret ederek düzenlemenin Anayasa'nın 67. maddesine aykırı olduğuna hükmetmiştir.

Bu çerçevede mektupla oy kullanma Türkiye mevzuatında an itibariyle uygulanabilir nitelikte değildir. Anayasa Mahkemesi iptal kararının farklı gerekçesinde, mektupla oy kullanma yönteminin anayasaya aykırılık gerekçesi gözetilerek yeni bir düzenleme yapılabileceğini işaret etmesine ve 09.05.2012 tarih ve 6304 sayılı Kanunla 298 sayılı Kanunun 94. maddesinde bir takım değişiklikler yapılmasına rağmen, mektupla oy kullanma usulü ile ilgili güvence getirici bir takım düzenlemeler yapmayı tercih etmeyerek mektupla oy verme usulünü tamamen terk etmiştir (TBMM Anayasa ve İçişleri Komisyonları, 2012).

\section{3 KASIM 2020 TARIHIINDE GERÇEKLEŞEN AMERİKA BİRLEŞİK DEVLETLERİ BAŞKANLIK SEÇIMLERININ ARDINDAN YAŞANAN GELIŞMELER}

3 Kasım 2020 tarihinde gerçekleşen Amerika Birleşik Devletleri Başkanlık seçimleri için Cumhuriyetçi Parti mevcut başkan Donald Trump'1, Demokrat Parti ise bir önceki başkan Barack Obama'nın yardımcısı olan Joe Biden'1 aday göstermiştir. Seçim sürecini daha önceki seçimlerden ayıran en önemli özelliklerden bir tanesi Covid-19 salgını sebebiyle oluşan yeni sosyal düzen olmuştur. Sosyal mesafe ve hijyen kuralları seçim sürecinde mektupla oy kullanma ve elektronik oy kullanma konusunu yoğun bir şekilde gündeme getirmiştir. İlk olarak 1864 Amerika İç Savaşı esnasında askerlere tanınan mektupla oy hakkı, günümüzde Amerika Birleşik Devletlerinin bazı eyaletlerinde herhangi bir mazeret olmasa dahi başvurabilecek bir oy verme yöntemi iken, bazı eyaletlerde Covid-19 salgını dâhil herhangi bir mazeret olması halinde başvurulabilecek bir oy verme yöntemdir.

Covid-19 salgını sebebiyle daha çok başvurulduğu değerlendirilen mektupla oy kullanma yöntemi Amerika'da Demokratlar ve Cumhuriyetçiler arasında yeni bir tartışma odağı haline gelmiş olup Trump "Mektupla oy kullanımı çok tehlikeli. Büyük sahtekârlık ve hukuksuzluğa yol açıyor" sözleriyle mektupla oy kullanma ile ilgili rahatsızlığı seçimden oldukça önce istikrarlı bir şekilde ifade etmiştir (Gültekin ve Kanat, 2020:39). Trump'ın seçim öncesi bu iddiaları dile getirmesinde mektup yoluyla oy kullanmanın yalnızca Demokratlar'a yarar sağlayacağına dair kanaatinin etkili olduğu söylenebilir.

3 Kasım 2020 tarihinde gerçekleşen Amerika Birleşik Devletleri başkanlık seçiminden önce 2020 yılı Nisan ayında Amerika Birleşik Devletlerinde mektupla oy verme ile ilgili yapılan bir araştırma Covid-19 salgınından kaynaklı oluşan durumun da etkisiyle mektupla oy vermenin seçmenlere oylarını kullanmak konusunda kolaylık sağladığı, katılım oranını 1lımlı bir şekilde arttırdığı, fakat herhangi bir adayın lehine veya aleyhine bir oy oranı oluşturacak nitelikte olmadığını yönünde verileri ortaya koymuştur (Thompson vd., 2020:13).

Donald Trump seçimlerin ardından elektronik oy kullanmaya ilişkin oy verme yazılımının 28 eyalette kendisine verilen milyonlarca oyu sildiğini (www.bbc.com, 2020) oyların Dominion adlı radikal sola ait kötü üne ve ekipmanlara sahip özel bir şirket tarafından tasnif edildiğini, seçim gecesinde kendine ait elektronik oylarının çalındığını fakat (Demokratların) yakalanmadıklarını ifade ederek mektupla gönderilen seçimlerin iğrenç bir şaka olduğunu açıklamıştır (www.cnnturk.com; www.trthaber.com, 2020).

Amerikan seçim sisteminde görev alan iki adet kurum bulunmaktadır. Bunlardan birincisi seçimlerin finansmanı ile görevli olan Federal Seçim Komisyonudur. İkincisi ise tamamen seçim idaresine adanmış tek federal kurum olan Seçim Yardım Komisyonu, Amerikan Seçim Yardımı Yasası'nın (Help America Vote Act) gereksinimlerini karşılamak için yönergeler geliştirerek, gönüllü oylama sistemi yönergelerini benimseyerek, oylama sistemlerini test ederek, akreditasyon vererek, seçim idaresi hakkında ulusal bir bilgi takas odası olarak hizmet veren, güvenli, doğru ve erişilebilir seçimleri kolaylaştırmakla görevli bağımsız, iki partili bir yapıya sahip olup Temsilciler Meclisi ve Senatodaki çoğunluk ve azınlık liderliğinin tavsiyeleri üzerine Başkan tarafindan atanan dört komisyon üyesinden oluşmaktadır. Mevcut üyelerden Thomas Hicks ve Christy Mc Cormick, Başkan Barack H. Obama tarafından 13 Ocak 2015 tarihinde, Benjamin Hovland ve Donald Palmer, 
Başkan Donald Trump tarafından 4 Şubat 2019 tarihinde Seçim Yardım Komisyonuna atanmışlardır (The United States Election Assistance Commission, 2019).

3 Aralık 2020 tarihinde Seçim Yardım Komisyon üyeleri yaptıkları basın açıklamasında 2020 başkanlık seçiminde kullanılan oylama sistemlerine tam güven içinde olduklarını açıkça ifade etmişlerdir (Hovland vd., 2020). Amerika Birleşik Devletleri Kongresinin Senato ve Temsilciler Meclisi kanadı, 6 Ocak 2021 günü yerel saat ile 13.00'da, Amerika Birleşik Devletleri Başkanlık seçim sonucu Anayasa gereği tescil etmek için toplandı. Aynı saatte Donald Trump daha önceden yaptığı çağrı üzerine Beyaz Saray önünde miting amaciyla toplanan kalabalığa seçimleri büyük bir farkla kendilerinin kazandığını ancak hile ve usulsüzlük yoluyla haklarının çalındığı, destekçilerinden Kongre'ye yürümelerini ve delege oylarının tescil edileceği oturumda kendi söylemlerine destek veren Cumhuriyetçi partili Kongre üyelerine cesaret vermelerini istedi (Doğru, 2021). $\mathrm{Bu}$ çağrı üzerine hareket eden onbinlerce gösterici Kongre binasına vardıklarında polis barikatlarını yıkarak Kongre binasını işgal ettiler. Çıkan olaylar neticesinde biri polis en az beş kişi öldü ve en az on beş polis yaralandi.

Hiç şüphesiz 3 Kasım 2020 tarihinde gerçekleşen Amerika Birleşik Devletleri başkanlık seçimi ardından yaşanan ve parlamento binasının işgaline kadar varan trajik olayları Donald Trump'ın siyasi tercihlerinden, kişiliğinden ve kampanya stratejisinden bağımsız değerlendirmek mümkün değildir. Fakat mektupla oy kullanma ve elektronik oy kullanma ile ilgili mevcut şüphe Donald Trump'ın iddialarına önemli bir mesnet teşkil etmiş olup, kitlesini yönlendirmesi konusunda önemli bir argüman haline gelmiştir.

Türkiye açısından TBMM Anayasa Komisyonu Raporunda, TBMM Genel Kurulu kararında ve Anayasa Mahkemesi kararında mektupla oy verme usulünün, seçmenin iradesini korumaya elverişli nitelikte olmadığına işaret edilmiştir. 2020 yılı Amerika Birleşik Devletleri Başkanlık seçimlerinin ardından yaşanan tartışmalar, konunun lojistik boyutu ile ilgili bir takım sorunların da yaşanabileceği düşüncesini ortaya koymaktadır.

Amerika Birleşik Devletleri Başkanlık seçimlerinde dört ay önce Amerikan Posta Hizmetleri, mektupla kullanılacak milyonlarca oyun, 3 Kasım'daki başkanlık seçim gününde sayılabilecek kadar erken ulaşmayabileceği, belli teslim tarihlerinin, Posta Hizmetleri'nin dağıtım standartlarına uygun düşmediği uyarısında bulunmuştur (www.tr.euronews.com, 2020).

Amerikan Posta Hizmetleri 2020 Başkanlık seçimlerinde olağanüstü bir çaba gösterdiklerini ifade ederek mektupla oy kullanmaya yönelik oy pusularının seçim kurullarından seçmenlere ulaşması için ortalama sürenin 2.1 gün olduğunu, oy pusularının seçmenlerden seçim kurullarına ulaşması için ortalama sürenin 1.6 gün olduğunu, oy pusularının seçmenlerden seçim kurullarına yedi gün içinde ulaşma oranını $\% 99.89$ olduğunu, oy pusularının seçmenlerden seçim kurullarına üç gün içinde ulaşma oranını $\% 97.9$ olduğunu açıklamasına rağmen (United States Postal Service, 2020:18) bir çok oyun posta gecikmeleri sebebiyle geçersiz sayıldığ 1 da iddia edilmiştir (www.washingtonpost.com, 2020).

\section{SONUÇ}

Seçimlere katılma oranının bireylerin kişisel tercihleri doğrultusunda artması olumlu bir gelişme olup, kamu otoritelerinin bunu kolaylaştırıcı ve teşvik edici nitelikte tedbirler alması önemlidir. Seçime katılma oranını arttırmak amacıyla Türkiyenin seçim mevzuatına giren mektupla oy verme usulü Anayasa Mahkemesi kararının ardından ortadan kaldırılmıştır. Anayasa Mahkemesi kararında ilave güvenceler alınarak mektupla oy kullanma usulüne başvurulabileceği ifade edilmesine rağmen, TBMM'de temsil edilen siyasi partiler mektupla oy verme usulü ile ilgili yeni veya ilave bir düzenleme yapma ihtiyacını bugüne kadar hissetmemişlerdir. TBMM'de temsil edilen siyasi partilerin bu zımni iradesi mektupla oy kullanmanın sakıncaları konusunda bir uzlaşmanın varlığına işaret etmektedir.

Özellikle elektronik oylama yöntemi ile ilgili olarak Türkiyede fen bilimleri (bilgisayar mühendisliği vb.) alanında yapılan araştırma ve çalışmalarda, elektronik oylama yönteminin avantajları ile ilgili bir çok argüman ortaya koysalar da, 3 Kasım 2020 tarihinde gerçekleşen Amerika Birleşik Devletleri başkanlık seçimi pratiği elektronik oylama yöntemi ve mektupla oy verme yönteminin alternatif maliyetinin oldukça yüksek olabileceğini göstermiştir.

Türkiye'deki mevcut seçim yönetim ve denetim sistemi uluslararası normlar ile genel itibariyle uyumludur. Türkiyede toplumun önemli çoğunluğunda da seçim sisteminin tarafsız ve bağımsız bir yapıda ve işlevde olduğu kanaati hâkimdir (Güler, 2021:157). Bu kanaat demokratik sistemimizin devamı için hayati öneme sahiptir. Bu niteliği örseleme potansiyeli olan tercihlere oldukça temkinli yaklaşılması gerekir. 
Bir ülkede uygulanmış veya uygulanmakta olan politikaların, yönetsel düzenlemelerin, programların, kurumların, stratejilerin politika transferine konu olabilecekleri (Uysal, 2020:937) gerçeği 1şığında 3 Kasım 2020 tarihinde gerçekleşen Amerika Birleşik Devletleri başkanlık seçimi sonucunda yaşanan olayların elektronik oylama yöntemi ve mektupla oy verme yöntemi açısından "ders çıkarma-lesson drawing" olarak değerlendirilmesi oldukça önemlidir.

Köklü ve uzun soluklu olması hedeflenen seçim kanunlarının seçim sath-1 mahalline girmeden, siyasi tansiyonun düşük olduğu dönemlerde, akademik perspektifi ve uygulama kabiliyetini harmanlayacak şekilde, normatif değerleri hedefleyen fakat ülke gerçekleri ve ihtiyaçlarına uygun, Türkiye Büyük Millet Meclisi içinde ve dişında mümkün olan en geniş uzlaşmayı içeren, çoğulcu bir zihniyetin ürünü olarak kabul edilmelerinde çok büyük fayda vardır (Güler, 2021:130). Bu çerçevede özellikle yurtdış1 seçmen kütüğüne kayıtlı seçmenin seçimlere katılımını arttırmak amacıyla birçok noktada sandık kurmak için fiziki imkânların mevcut olduğu ve yeteri kadar insan kaynağı bulunduğu ülkelerde, 298 sayılı Kanunun 94. maddesinin "ihtiyaç duyulması halinde yerel makamların uygun göreceği diğer yerlerde sandık kurulmasına" imkân veren hükme işlerlik sağlanması değerlendirilmelidir.

\section{KAYNAKÇA}

AKIN, Melda (2006), "Elektronik Oy Verme Sistemlerinde Güvenlik: Deneyimler ve Türkiye Için Öneriler", İstanbul Üniversitesi İktisat Fakültesi Ekonometri ve İstatistik Dergisi, S.3, ss.32-47.

ARSLAN, Ali (2007), "1950'den 12 Eylül 1980 Askeri Müdahalesine, Genel Seçim Sonuçları Temelinde Trükiye'nin Siyasi Yapısı", Uluslararası İnsan Bilimleri Dergisi, S.4(1), ss.1-29.

BBC (2020), "ABD Seçim Sonuçları: Seçim Güvenliği Yetkilileri, Trump’ın Hile Iddialarını Reddetti", EHaber, https://www.bbc.com/turkce/haberler-dunya-54928556 (Erişim Tarihi: 13.11.2020).

BERINSKY, Adam, BURNS, Nancy ve TRAUGOTT, Michael (2001), "Who Votes by Mail?: A Dynamic Model of the Individual-Level Consequences of Voting-by-Mail Systems", The Public Opinion Quarterly, S.65(2), ss.178-197.

BİLGiN, Metin, ALTUN, Adem Alpaslan, IŞIK, Hakan ve SUNGUR, Cemil (2009), "Biyometrik Doğrulama Tabanlı Seçim Sistemi", Selçuk-Teknik Dergisi, S.8(1), ss.74-93.

CNNTURK (2020), "ABD Başkanı Trump Seçimlere Hile Karıştırıldı̆̆ı İddiasını Yineledi", E-Haber, https://www.cnnturk.com/dunya/abd-baskani-trump-secimlere-hile-karistirildigi-iddiasini-yineledi (Erişim Tarihi: 12.11.2020).

ÇETINKAYA, Deniz ve ÇETINKAYA, Orhan (2006), "E- Seçim Uygulamaları İçin Gereksinimler ve Tasarım Illkeleri", XI. Türkiye'de İnternet Konferansı Bildiriler Kitabı, 21-23 Aralık 2006 - Ankara, ss.1-8, https://user.ceng.metu.edu.tr/ corhan/Papers/inettr06.pdf (Erişim Tarihi: 03.08.2020).

ÇOKLUK, Nil ve ÖZDEMIR, Merve (2019), "Demokrasi ve Siyasal Katılımda Yeni Bir Boyut: Elektronik Demokrasi ve Elektronik Seçimler", SADAB 3rd International Social Research and Behavioral Sciences Symposium, 20-21Nisan 2019 - Saraybosna (Bosnia and Herzegovina), ss.94-119.

DOĞRU, İslam (2021), "ABD'de Yaşanan Kongre Baskını Trumpizm'in Sonunun Başlangıcı Olabilir Mi?" Anadolu Ajansi, 08.01.2021, https://www.aa.com.tr/tr/analiz/abdde-yasanan-kongre-baskinitrumpizmin-sonunun-baslangici-olabilir-mi/2102830 (Erişim Tarihi: 03.08.2020).

ERDEM, Ayhan ve ERKAYMAZ, Okan (2009), "Genel ve Yerel Seçimler İçin Web Tabanlı Uygulama: ESeçim", Technological Applied Sciences, S.4(2), ss.136-150.

ERZURUMLU, Kerem ve KOLOĞLU, Tevfik Fikret (2017), "Türkiye'de E-Seçim Sisteminin Uygulanabilirliğiyle İlgili Çalışma ve Uygulama Geliştirme", 19. Akademik Bilişim Konferansı Bildiriler Kitabı, 04-11 Şubat 2017 - Aksaray, Aksaray Üniversitesi Yayını, ss.1-7.

EURONEWS (2020), "ABD Posta Hizmetleri'nden 3 Kastm Seçimi Duyurusu: Mektupla Verilen Oylar Zamanında Ulaşmayabilir", E-Haber, https://tr.euronews.com/2020/08/16/abd-posta-hizmetleri-nden-3kas-m-secimi-duyurusu-mektupla-verilen-oylar-zaman-nda-ulasmay (Erişim Tarihi: 16.08.2020).

GÖZLER, Kemal (2020), Anayasa Hukukunun Genel Teorisi, Ekin Yayınları, Bursa. 
GÜLER, Fatih (2021), Seçimlerin Yönetim ve Denetiminde Görev Alan Kurumların Yapısal ve İşlevsel Sorunlarını Giderici Çözümler, Ekin Yayınları, Bursa.

GÜLTEKİN, Elif ve KANAT, Buğra (2020), 2020 ABD Başkanlık Seçimi, Siyaset, Ekonomi ve Toplum Araştırmaları Vakfı Yayını, Ankara.

HOVLAND, Benjamin W., PALMER, Donald L., HICKS, Thomas ve McCORMICK, Christy (2020), "How the U.S. Election Assistance Commission Facilitates Fair and Secure Elections", Election Assistance Commission Statement, 03.12.2020, https://www.eac.gov/news/2020/12/03/how-us-election-assistancecommission-facilitates-fair-and-secure-elections (Erişim Tarihi: 03.08.2020).

KİRIŞ, Hakan Mehmet (2015), "Türkiye'de 'Seçim Sandiğı' Tartışmaları: Seçime Katılma Oranlarının Anlamı ve Önemi", Toplum ve Demokrasi Dergisi, S.9(20), ss.25-49.

RİCHEY, Sean (2008), "Voting by Mail: Turnout and Institutional Reform in Oregon", Social Science Quarterly, S.89(4), ss.902-915.

SARIBAY, Ali Yaşar (1998), Siyaset Sosyolojisi, Der Yayınları, İstanbul.

SOUTHWELL, Prisc1lla ve BURCHETT, Justin (2000), "The Effect of All-Mail Elections on Voter Turnout", American Politics Quarterly, S.28(1), ss.72-79.

TBMM ANAYASA KOMISYONU (2008), Seçimlerin Temel Hükümleri ve Seçmen Kütükleri Hakkında Kanunda Değişiklik Yapılmasına Dair Kanun Tasarısı ve Türkiye Büyük Millet Meclisi 23 . Dönem 2. Yasama Yılı Anayasa Komisyonu Raporu, S.110(1/498), TBMM Yayını, Ankara.

TBMM ANAYASA VE İÇIŞLERİ KOMİSYONLARI (2012), Türkiye Büyük Millet Meclisi 24. Yasama Dönemi 2. Yasama Yılı Seçimlerin Temel Hükümleri ve Seçmen Kütükleri Hakkında Kanun ile Bazı Kanunlarda Değişiklik Yapılmasına Dair Kanun Tasarısı ve İçişleri Komisyonu ile Anayasa Komisyonu Raporları, S.1/564, TBMM Yayını, Ankara.

TBMM GENEL KURULU (2008a), "23. Dönem, 2. Yasama Yılı, 70. Bileşim Meclis Genel Kurulu Tutană̆ı", Türkiye Büyük Millet Meclisi Tutanak Dergisi, Cilt.15, 27 Şubat 2008.

TBMM GENEL KURULU (2008b), "23. Dönem, 2. Yasama Yıll, 77. Bileşim Meclis Genel Kurulu Tutanağı", Türkiye Büyük Millet Meclisi Tutanak Dergisi, Cilt.16, ss.474-490.

TELCILLER, Coşkun (2017), "Elektronik Seçim Sistemleri, Sorunlar, Çözüm Önerileri", Nişantaşı Üniversitesi Sosyal Bilimler Dergisi, S.5(2), ss.106-122.

THE UNITED STATES ELECTION ASSISTANCE COMMISSION (2019), EAC's Commissioners, https://www.eac.gov; https://www.eac.gov/about_the_eac/commissioners.aspx (Erişim Tarihi: 03.12.2020).

THE UNITED States POSTAL SERVİCE (2020), 2020 Post-Election Analysis: Delivering The Nation's Election Mail In An Extraordinary Year, United State Postal Service Publisher, Washington D.C..

THOMPSON, Daniel M., WU, Jennifer A., YODER, Jesse ve HALL, Andrew B. (2020), "The Neutral Partisan Effects of Vote-By-Mail:Evidence From County-Level Rollouts", Stanford Institute For Economic Policy Research, S.117(25), ss.14052-14056.

TRTHABER (2020), "ABD Başkanı Trump Seçimlere Hile Karıştırıldı̆̆ı İddiasını Yineledi", E-Haber, https://www.trthaber.com/haber/dunya/abd-baskani-trump-secimlere-hile-karistirildigi-iddiasini-yineledi531091.html (Erişim Tarihi: 15.11.2020).

UYSAL, Yusuf (2020), "İngiltere Kamu - Özel İşbirliği Modelinin Türkiye'deki Şehir Hastaneleri Uygulamaları Üzerine Etkileri: Politika Transferi Bağlamında Bir Analiz", Dokuz Eylül Üniversitesi Sosyal Bilimler Enstitüsü Dergisi, S.22(3), ss.935-960.

WASHINGTONPOST (2020), "USPS Processed 150,000 Ballots After Election Day, Jeopardizing Thousands of Votes", E-Article, https://www.washingtonpost.com/business/2020/11/05/usps-late-ballots-election/ (Erişim Tarihi: 06.11. 2020).

YÜCEL, Bülent (2013), "Seçimlere Katılma Oranının Siyasi Sisteme Etkisi Üzerine Gözlemler", Yasama Dergisi, S.24, ss.7-36. 